\title{
A hederagenin saponin isolated from Clematis ganpiniana induces apoptosis in breast cancer cells via the mitochondrial pathway
}

\author{
LIN CHENG $^{1,2}$, LIANG SHI ${ }^{1}$, JING WU $^{1}$, XUJIE ZHOU ${ }^{1}$, XIAOXIA LI ${ }^{1}$, \\ $\mathrm{XI} \mathrm{SUN}^{1}$, LEI ZHU ${ }^{1}$, TIAN-SONG XIA ${ }^{1}$ and QIANG DING ${ }^{1}$ \\ ${ }^{1}$ Jiangsu Breast Disease Center, The First Affiliated Hospital with Nanjing Medical University, \\ Nanjing, Jiangsu 210029; ${ }^{2}$ Department of Breast Surgery, Changzhou No. 2 People's Hospital, \\ Affiliated to Nanjing Medical University, Changzhou, Jiangsu 213000, P.R. China
}

Received April 20,2017; Accepted November 20, 2017

DOI: $10.3892 / \mathrm{ol} .2017 .7494$

\begin{abstract}
Natural plants offer a treasure trove of resources for anticancer drug development. Clematis are widely used in Traditional Chinese Medicine. However, studies on the active substances in Clematis are scarce. In the present study, four monomer compounds were successfully extracted from this species and their inhibitory effects on the growth of breast cancer cells were investigated using bioactivity tests. Among them, Clematis hederagenin saponin (CHS) belongs to the class of triterpenoid saponins. CHS showed cytotoxic effects on breast cancer cells in a dose- and time-dependent manner. The compound also induced apoptosis in breast cancer cells in a time-dependent manner. Further investigation into the underlying mechanisms of apoptosis induction in breast cancer cells showed that the compound significantly reduced mitochondrial Apaf-1 and cytochrome $c$ proteins in breast cancer cells. In addition, it upregulated the activities of caspase-3 and -9 . In conclusion, CHS induced apoptosis in breast cancer cells through regulation of the mitochondrial apoptosis pathway. The results suggest that the hederagenin saponin extracted from Clematis ganpiniana offers great potential as a novel anti-breast cancer drug.
\end{abstract}

\section{Introduction}

Breast cancer is currently the most common form of cancer and the second-leading cause of death from cancer in women (1). Comprehensive treatment strategies using surgery in combination with chemotherapy, radiotherapy,

Correspondence to: Dr Qiang Ding or Dr Tian-Song Xia, Jiangsu Breast Disease Center, The First Affiliated Hospital with Nanjing Medical University, 300 Guangzhou Road, Nanjing, Jiangsu 210029, P.R. China

E-mail: dingqiang@njmu.edu.cn

E-mail: xiatsswms@163.com

Key words: clematis hederagenin saponin, breast cancer, apoptosis, mechanism, mitochondria and endocrine therapy have achieved significant progress in improving the outcome of breast cancer (2). This can be attributed not only to the continuous improvement of surgical techniques and methods but also to the improved efficacy of chemotherapy-based adjuvant therapy in controlling the progression of primary lesions and tumor recurrence and metastasis (3). However, clinical challenges, such as cancer recurrence and metastasis, caused by chemotherapy failure need to be addressed immediately (4).

Natural plants offer a treasure trove of resources for antitumor drug development (5). Currently, exploring natural plant-derived antitumor drugs with definitive efficacy, high efficiency, and low toxicity has become one of the most popular research topics in breast cancer treatment (6). China has abundant sources of medicinal species and a long history of using medicinal plants for anticancer treatment. There are various successful examples of medicinal monomer compounds, such as ginsenoside Rh2 (7) and tanshinone IIA (8) that have been developed and applied to tumor treatment. In 1967, the US National Cancer Institute discovered taxol, which was isolated from the bark of the Pacific yew (9). Since then, more than 30 research groups worldwide have successfully semi-synthesized or fully synthesized taxol or both, and Taxol quickly became the first-line drug for adjuvant therapy of various tumors including breast cancer (10).

Clematis belongs to the family Ranunculaceae and has $\sim 355$ species worldwide. China is home to 155 species, of which $\sim 70$ are widely used in traditional Chinese medicine (TCM) (11). The TCM drug Radix Clematidis recorded in the Chinese Pharmacopoeia is isolated from the dried roots and rhizomes of Clematis chinensis Osbeck, Clematis mandshurica Rupr, and Clematis hexapetala Pall. This drug has analgesic, sedative, antibacterial, anti-inflammatory, and diuretic effects (People's Republic of China Pharmacopoeia Commission, 2005). Currently, studies on the active substances in Clematis are scarce. We conducted a preliminary research study on Clematis plants that are included in an antitumor treatment formula by the Naxi ethnic group (Yunnan, China) (11). We have successfully extracted four monomer compounds from this species, and their inhibitory effects on the growth of breast cancer cells were proven by using bioactivity tests $(11,12)$. 
Among them, Clematis hederagenin saponin (hederagenin $3 \beta-\mathrm{O}-\alpha-\mathrm{L}$-arabinopyranoside, $\mathrm{CHS}$ ) belongs to the class of triterpenoid saponins $(13,14)$. Triterpenoid saponins show bioactivities against various types of malignancies including breast, colon, and lung cancers (15). Numerous noteworthy studies have revealed that triterpenoid saponin compounds have relatively high anti-breast cancer activity and could be potential drugs that would contribute to chemoprevention and treatment of breast cancer (16). Previous studies have found that triterpenoid saponin compounds can exert an inhibitory effect on numerous types of cancers by regulating different signaling pathways, such as the epidermal growth factor receptor (EGFR), estrogen receptor (ER) $(16,17)$, and Fas/Fas ligand (FasL) pathways (18). However, to the best of our knowledge, studies on the triterpenoid saponins extracted from Clematis ganpiniana are very scarce, and those on the antitumor mechanism of Clematis species are even fewer.

This is an original research study on the pro-apoptotic effect of saponins from the Clematis vine on breast cancer cells and an exploration of the apoptotic pathways involved. Cell apoptosis and proliferation are two basic physiological processes, which are also basic measures that maintain the dynamic equilibrium of the number of cells in the body. There are two main apoptotic pathways: One involves intracellular caspases activated by extracellular signals while the other involves caspases activated by mitochondria-derived activators of caspase. Activated caspases can degrade key cellular proteins, thereby causing apoptosis $(19,20)$. Considering the lack of research on the effect and the underlying mechanisms of saponins extracted from Clematis vine on breast cancer cells, we investigated the role of this compound in inducing apoptosis of breast cancer cells by using MCF-7 and MDA-MB-231 breast cancer cell lines as experimental models. Moreover, because of the pivotal role of the mitochondrial pathway in apoptosis, the study was focused particularly on the effect of this compound on the mitochondrial pathway to further clarify its antitumor mechanisms.

\section{Materials and methods}

Compound preparation. The extraction and purification of CHS were conducted using the method previously described in the literature (11) and the chemical structure of the saponin is shown in Fig. 1. The extracted compound was dissolved in $100 \%$ dimethyl sulfoxide (DMSO) and stored at $-20^{\circ} \mathrm{C}$. Before use, the drug was dissolved in culture medium to final concentrations of $0.08,0.4,2$ and $10 \mu \mathrm{g} / \mathrm{ml}$. Cells treated with only DMSO were used as the control. The possible cytotoxic effects of DMSO were minimized by ensuring a final DMSO concentration $\leq 0.1 \%(\mathrm{v} / \mathrm{v})$.

Cell culture. MCF-7 and MDA-MB-231 breast cancer cell lines (ATCC, Manassas, VA, USA) were cultured in Dulbecco's modified Eagle's medium (DMEM) containing 10\% fetal bovine serum (FBS), $100 \mathrm{U} / \mathrm{ml}$ penicillin, and $100 \mathrm{~g} / \mathrm{ml}$ streptomycin at $37^{\circ} \mathrm{C}$ in an atmosphere of $5 \% \mathrm{CO}_{2}$.

For routine passages, cultures were split 1:3 when they reached $80-90 \%$ confluence generally every 2-3 days. All experiments were performed on exponentially growing cells. Two breast cancer cell lines MCF-7 and MDA-MB-231 which represented different phenotypes of this heterogeneous disease, were used to evaluate the growth inhibition and to explore the underlying molecular mechanisms of CHS.

Main reagents. The reagents and kits used in this study included DMEM (Hyclone Laboratories, Inc., Logan, UT, USA), FBS (Wisent, Nanjing, China), trypsin, DMSO, 3-(4,5-dimethylthiazol-2-yl)-2,5-diphenyltetrazolium bromide (MTT) (Beyotime Institute of Biotechnology, Nanjing, China), mitochondrial protein extraction kit (KeyGen Biotech Co., Ltd., Nanjing, China), and Annexin V-FITC apoptosis detection kit (Bender Medsystems, San Diego, CA, USA). Target antibodies, including anti-Apaf-1 and anti-cytochrome c (Cyto C) primary antibodies, were all purchased from Cell Signaling Technology, Inc. (Danvers, MA, USA). The secondary antibody used was horseradish peroxidase (HRP)-goat anti rabbit IgG (Cell Signaling Technology, Inc.). $\beta$-actin (Beyotime Institute of Biotechnology) was used as an internal standard. The enhanced chemiluminescence (ECL) kit and polyvinylidene fluoride (PVDF) membranes were both purchased from Pierce (Rockford, IL, USA) and EMD Millipore (Billerica, MA, USA), respectively.

Cytotoxic effect assay (MTT assay). Cells were collected and diluted with culture medium to a density of $10^{5}$ cells $/ \mathrm{ml}$, and then seeded into 96-well plates at $100 \mu \mathrm{l} /$ well. The cells were cultured overnight to $70 \%$ confluence, and treated with $0.08,0.4,2$, or $10 \mu \mathrm{g} / \mathrm{ml} \mathrm{CHS}$. Each concentration was tested in triplicate. Subsequently, the cells were cultured in vitro for 12,24 , or $48 \mathrm{~h}$. Breast cancer cells cultured in medium with $0.05 \%$ DMSO as a negative control for this experiment. After treatment, the culture medium in each well was discarded and replaced with $180 \mu \mathrm{l}$ of fresh culture medium and $20 \mu \mathrm{l}$ of MTT $(5 \mathrm{mg} / \mathrm{ml})$. The cells were incubated at $37^{\circ} \mathrm{C}$ for $4 \mathrm{~h}$, after which the culture medium was discarded and $150 \mu \mathrm{l}$ of DMSO was added to each well. The samples were placed on a shaker for $15 \mathrm{~min}$ and and then read at $490 \mathrm{~nm}$ with a microplate reader (5082; Tecan Austria GmbH, Grödig, Austria). Cell survival rate was calculated as OD of the experiment samples/OD of the control x 100 .

Detection of the apoptosis rate using flow cytometry. After exposure to $2 \mu \mathrm{g} / \mathrm{ml} \mathrm{CHS}$ for 6,12 and $24 \mathrm{~h}$, the breast cancer cells were collected and centrifuged. Approximately $10^{5}$ cells were analyzed for each treatment. After the supernatant was discarded, the treated cells were trypsinized and washed three times with PBS, followed by the addition of Annexin V-FITC and propidium iodide (PI). The cells were then kept in the dark at room temperature for $10 \mathrm{~min}$ prior to evaluation using flow cytometry to determine the apoptosis rate. Annexin V can bind to phosphatidylserineand PI can easily enter dead or damaged cells. The combination of the two dyes can be used to detect cellular apoptosis. FITC-positive cells are the cells in the early stage of apoptosis, while PI-positive staining indicates dead cells. The cells stained with both are in the late stage of apoptosis, while cells that not stained by either are normal, live cells.

Detection of caspase-3 and -9 activity using flow cytometry. After treatment ( $24 \mathrm{~h}$ of exposure to $2 \mu \mathrm{g} / \mathrm{ml} \mathrm{CHS}$ ), the breast 
cancer cells were collected and centrifuged. After the supernatant was discarded, the treated cells were trypsinized and resuspended in PBS. Next, $300 \mu 1$ of each sample was added to a centrifuge tube and mixed with $100 \mu \mathrm{M}$ RED-DEVD-FMK (caspase-3) or RED-LEHD-FMK (caspase-9), and incubated at $37^{\circ} \mathrm{C}$ for $30 \mathrm{~min}$. After centrifugation, the supernatant was discarded and the cell pellets were washed twice with $500 \mu \mathrm{l}$ of wash buffer. Subsequently, the cells were resuspended and subjected to flow cytometry to detect the number of positively stained cells. Z-DEVD-FMK is a caspase-3 inhibitor and Z-LEHD-FMK is a caspase-9 inhibitor, both of which can inhibit apoptosis caused by caspase activation. To determine the inhibitor-induced change in caspase activity, the cells in the two treatment groups were pretreated with one of the two inhibitors $(100 \mu \mathrm{M})$ for $1 \mathrm{~h}$ prior to the CHS treatment $(2.0 \mu \mathrm{g} / \mathrm{ml})$. What's more, after exposure to $10 \mu \mathrm{g} / \mathrm{ml} \mathrm{CHS} \mathrm{for}$ $24 \mathrm{~h}$, breast cancer cells (with or without pre-incubated with caspase inhibitors $1 \mathrm{~h}$ before CHS treatment) were resuspended in stain containing Annexin V-FITC/PI and analyzed with FACSAria flow cytometer using FACSDiva software.

Western blotting (WB) assay. MCF-7 and MDA-MB-231 cells were seeded at $1 \times 10^{6}$ cells in $100 \mathrm{~mm}^{2}$ dishes. Cells were treated in complete medium with CHS for 2, 6, 12 and $24 \mathrm{~h}$. After treatment, the cells treated with the compound (or control) were collected, washed once with PBS, and centrifuged at 1,500 rpm for $5 \mathrm{~min}$. The supernatant was discarded. A mitochondrial protein extraction kit (Beyotime Institute of Biotechnology) was used to extract mitochondrial proteins from cells in accordance with the manufacturer's instructions. Briefly, after exposure, MCF-7 and MDA-MB-231 cells were harvested and centrifuged at $800 \mathrm{x}$ g at $4^{\circ} \mathrm{C}$ for $10 \mathrm{~min}$. The pellets were added with $20 \mathrm{mM}$ N-2-hydroxyethylpiperazine-N0-20-ethanesulfonic acid (HEPES) buffer containing protease inhibitor cocktail and disrupted with a glass tissue grinder. Homogenates were centrifuged at $800 \times \mathrm{g}$ at $4^{\circ} \mathrm{C}$ for $10 \mathrm{~min}$, and the resulting supernatants were transferred to $0.5 \mathrm{ml}$ conical tubes, and further centrifuged at $10,000 \mathrm{x}$ g at $4^{\circ} \mathrm{C}$ for $20 \mathrm{~min}$. The final pellets, containing the mitochondrial fraction, were analyzed for protein content using the Bradford method.

After protein quantification using the bicinchoninic acid (BCA) method, the samples were added to $5 \mathrm{X}$ protein loading buffer, boiled for $5 \mathrm{~min}$ to sufficiently denature proteins, and then stored at $-70^{\circ} \mathrm{C}$. Forty micrograms of protein was loaded into each lane for sodium dodecyl sulfate polyacrylamide gel electrophoresis (SDS-PAGE). Next, the separated proteins were blotted onto a PVDF membrane by wet transfer. After a $2 \mathrm{~h}$ block at room temperature to eliminate non-specific signals, the membrane was incubated with the primary anti-Apaf-1 or anti-Cyto $\mathrm{C}(1: 1,000)$ antibodies at $4{ }^{\circ} \mathrm{C}$ overnight, followed by three 5 min washes. Subsequently, the membrane was incubated with secondary antibodies $(1: 1,000)$ at room temperature for $2 \mathrm{~h}$, followed by three $10 \mathrm{~min}$ washes. $\beta$-actin $(1: 1,000)$ was used as a standard to ensure equal loading of protein into each lane of the gel. Finally, the protein signal was visualized by using ECL reagent and an automated chemiluminescence gel imaging system.

Statistical analysis. SPSS 20.0 statistical software (SPSS Inc., Chicago, IL, USA) was used for statistical analysis. The results

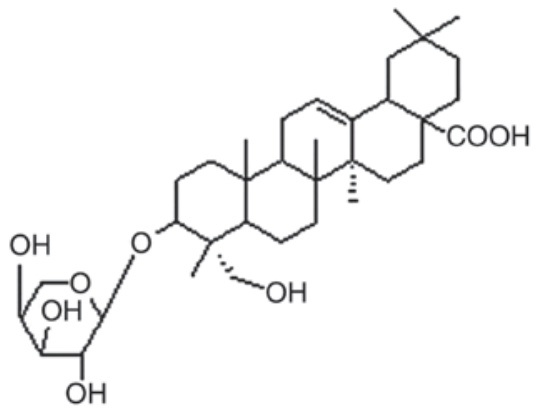

Figure 1. Chemical structure of CHS. CHS, Clematis hederagenin saponin.

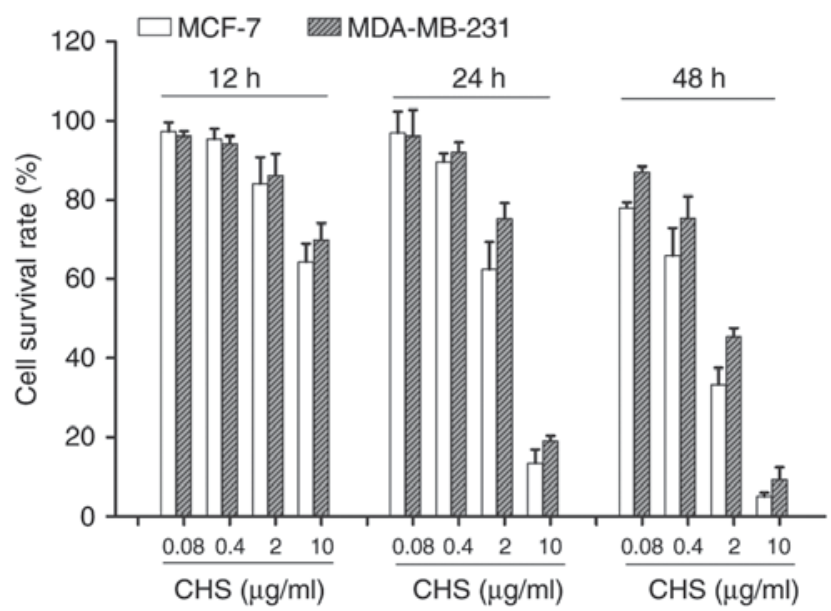

Figure 2. CHS showed cytotoxic effect on breast cancer cells. MTT assay of MCF-7 and MDA-MB-231 cells treated by various concentrations $(0.08,0.4$, $2,10 \mu \mathrm{g} / \mathrm{ml}$ ) of CHS for 12,24 and $48 \mathrm{~h}$. CHS showed cytotoxic effect on both types of breast cancer cells in a time- and dose-dependent manner $(\mathrm{P}<0.05)$. Cell survival rates were shown in column statistics. Data are mean \pm standard error of mean (SEM) of three independent experiments. CHS, Clematis hederagenin saponin.

were expressed as mean \pm standard deviation. One-way analysis of variance (ANOVA) was used for intergroup comparisons, followed by pairwise comparisons between groups. The results were expressed as mean \pm standard deviation (mean \pm SD). $\mathrm{P}<0.05$ was considered to indicate a statistically significant difference.

\section{Results}

CHS showed cytotoxic effect on breast cancer cells. In this study, MCF-7 and MDA-MB-231 breast cancer cells were used to evaluate the anticancer effect of CHS. Compared to the negative control group, CHS showed cytotoxic effect on both types of breast cancer cells after 12, 24 and $48 \mathrm{~h}$ of treatment, in a time- and dose-dependent manner $(\mathrm{P}<0.05)$ (Fig. 2).

CHS induced apoptosis in breast cancer cells. After 6, 12, and $24 \mathrm{~h}$ of treatment with $2.0 \mu \mathrm{g} / \mathrm{ml} \mathrm{CHS,} \mathrm{MCF-7} \mathrm{and}$ MDA-MB-231 cells were evaluated using flow cytometry to determine the apoptosis rate. The results showed that CHS induced apoptosis in breast cancer cells and the apoptosis rate increased over time. MCF-7 and MDA-MB-231 cells treated with $2.0 \mu \mathrm{g} / \mathrm{ml} \mathrm{CHS}$ for $24 \mathrm{~h}$ showed an early apoptosis rate of 
A
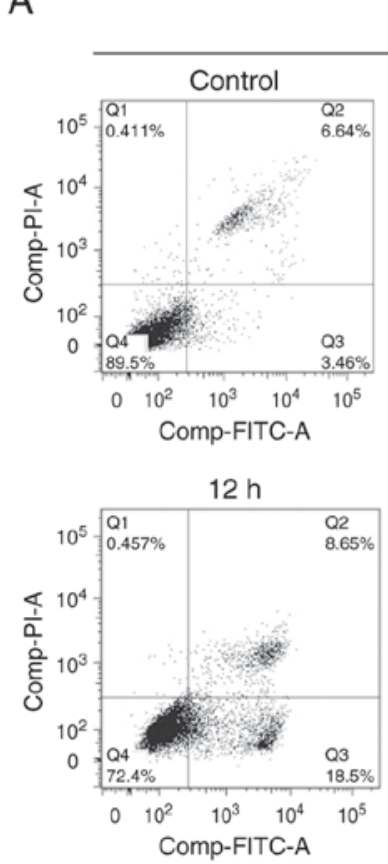

MCF-7
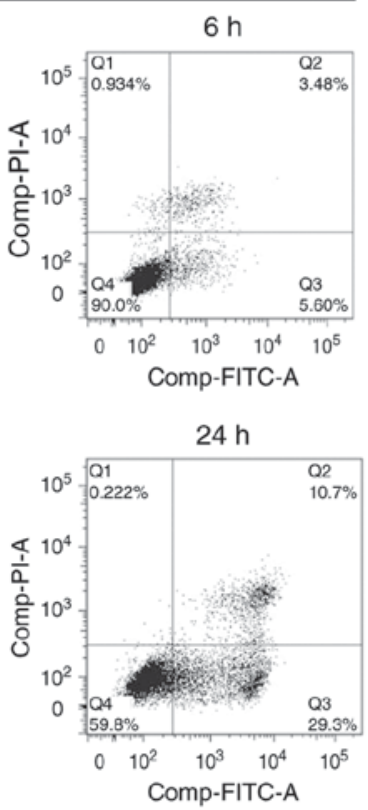

C

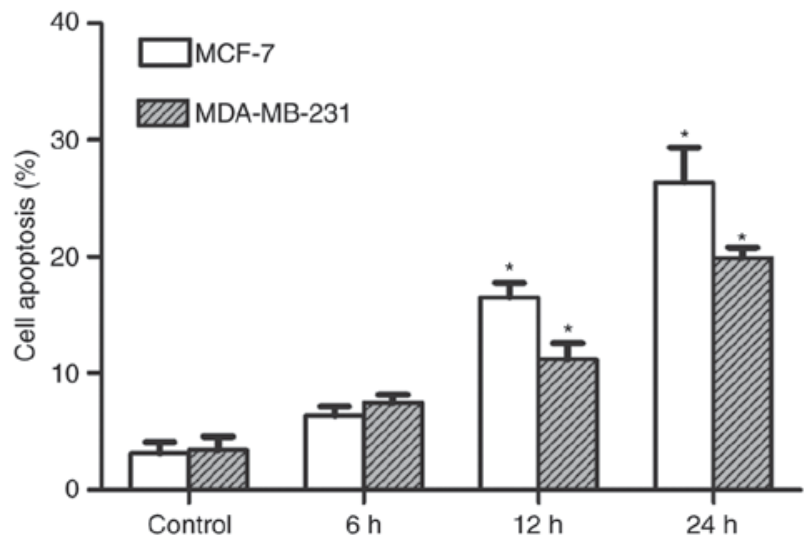

$\mathrm{B}$

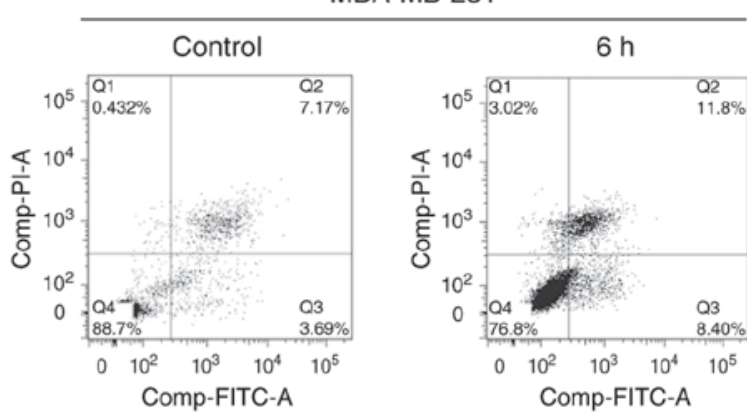

$12 \mathrm{~h}$
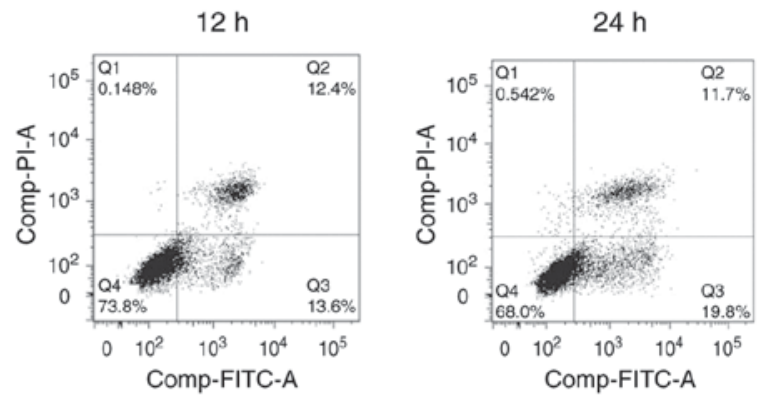
induced early apoptosis in MCF-7 and MDA-MB-231 cells. (C) Early apoptosis rate of MCF-7 and MDA-MB-231 cells treated with CHS of three independent experiments were shown in column statistics. Data are mean \pm SEM of three independent experiments. ${ }^{*}<0.05$ vs. CHS-untreated group. CHS, Clematis hederagenin saponin.

29.3 and $19.8 \%$, respectively (Fig. 3A and B). Early apoptosis rate of cells treated with CHS of three independent experiments were shown in column statistics (Fig. 3C).

CHS upregulated the activity of caspase-3 and caspase-9 in breast cancer cells. After treatment with CHS $(2.0 \mu \mathrm{g} / \mathrm{ml})$ for $24 \mathrm{~h}$, the breast cancer cells were subjected to RED-DEVD-FMK (caspase-3) or RED-LEHD-FMK (caspase-9) staining and flow cytometry to determine the changes in caspase activity. The results confirmed that CHS increased both caspase-3 and -9 activity in breast cancer cells. In the inhibitor-pretreatment groups, both caspase-3 and -9 inhibitors showed an inhibitory effect on the CHS-induced increase of caspase activity (Fig. 4A and B). Caspase-3, -9 positive rate of cells treated with CHS with/without caspase inhibitors of three independent experiments were shown in column statistics (Fig. 4C and D). Moreover, both caspase-3 and -9 inhibitors reduced CHS-induced apoptosis (Fig. 4E), which demonstrated that caspase-3 and -9 activation were involved in CHS-induced apoptosis.

CHS regulated the mitochondrial Apaf-1 and Cyto c level. MCF-7 and MDA-MB-231 cells were treated for 2, 6, 12 or $24 \mathrm{~h}$ with CHS $(2 \mu \mathrm{g} / \mathrm{ml})$ and both mitochondrial Apaf-1 and Cyto $\mathrm{C}$ level were detected by western blotting. CHS significantly reduced mitochondrial Apaf-1 and Cyto C proteins in breast cancer cells, indicating the enhanced release of Apaf-1 and Cyto $\mathrm{C}$ from mitochondria in breast cancer cells (Fig. 5A). After the cells were treated with the compound for 2 to $24 \mathrm{~h}$, there was gradual ruduction of mitochondria Apaf-1 and Cyto C proteins. Expressions of mitochondrial Apaf-1 andCyto $\mathrm{C}$ of cells treated with CHS 

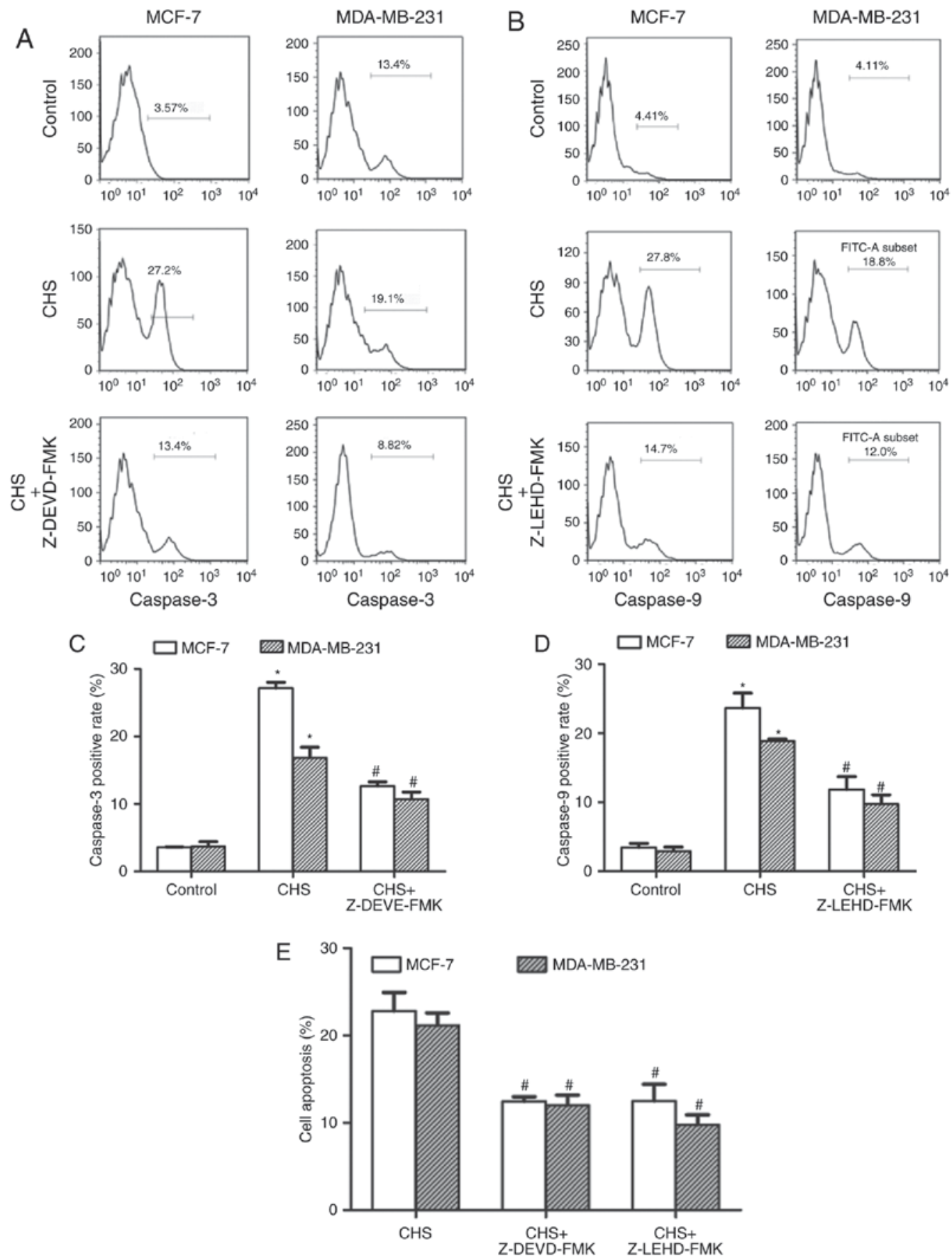

Figure 4. CHS increased the activity of caspase-3 and -9 of MCF-7 and MDA-MB-231 cells. (A and B) Effect of CHS on caspase-3 and -9 activation. CHS increased the activity of caspase-3 and -9 in both MCF-7 and MDA-MB-231 cells. This activation could be reversed by the caspase inhibitors respectively (C and D) Caspase-3, -9 positive rate of cells treated with CHS with/without caspase inhibitors of three independent experiments were shown in column statistics. (E) Caspase-3 and -9 inhibitors reduced CHS-induced apoptosis. ${ }^{\prime} \mathrm{P}<0.05$ vs. CHS-untreated group; ${ }^{*} \mathrm{P}<0.05$ vs. CHS-treated alone group. CHS, Clematis hederagenin saponin.

of three independent experiments were shown in column statistics (Fig. 5B and C).

\section{Discussion}

In this study, we discovered that CHS, a new type of triterpenoid saponin, showed strong cytotoxic effect on various types of breast cancer cells. CHS can induce apoptosis in both ER $^{+}$MCF-7 breast cancer cells and ER ${ }^{-}$MDA-MB-231 breast cancer cells. Further, we found that the mechanisms underlying the induction of apoptosis by CHS involved the regulation of caspase- 3 and -9 activity and the reduction of mitochondrial Apaf-1 and Cyto C proteins in breast cancer cells.

Recent studies have found that monomer components extracted from Clematis ganpiniana can suppress cell proliferation and promote cell apoptosis in malignant tumors. For example, Clematis montana lectin can induce apoptosis in MCF-7 breast cancer cells in a dose-dependent manner (21). Polygonatum cyrtonema lectin, a mannose-binding lectin can induce apoptosis and autophagy in A375 melanoma 
A

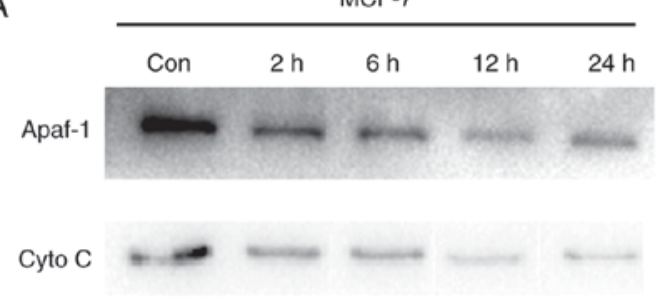

$\beta$-actin

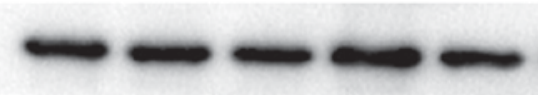

$\mathrm{B}$

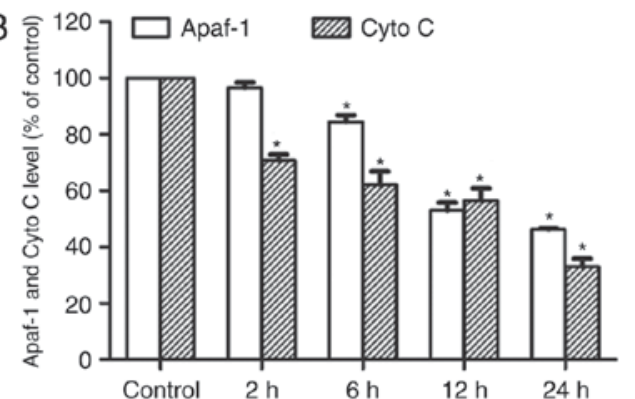

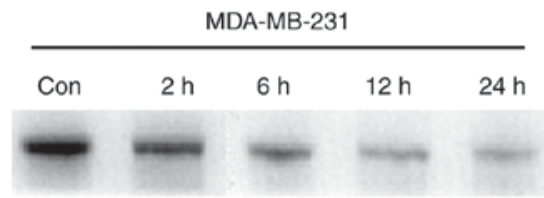
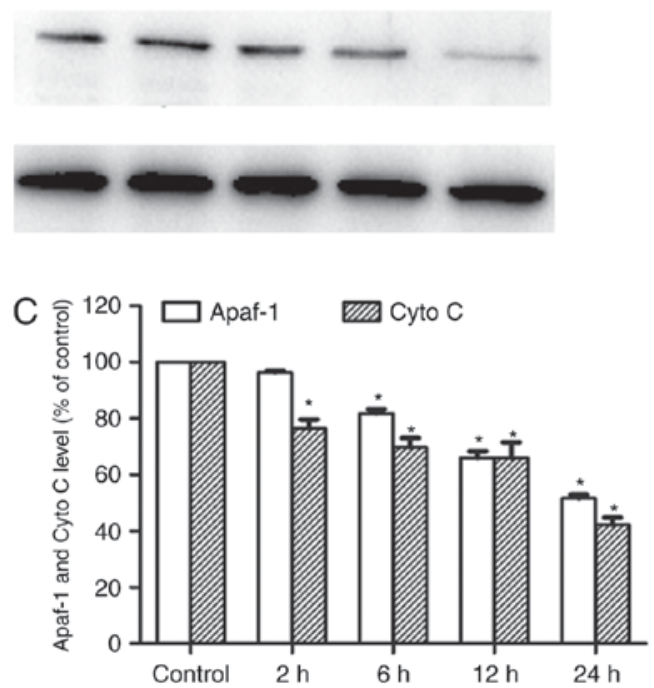

Figure 5. CHS decreased mitochondrial Apaf-1 and Cyto C expressions of MCF-7 and MDA-MB-231 cells. (A) Effect of CHS on reduction of mitochondrial Apaf-1 and Cyto $\mathrm{C}$ release. CHS decreased both mitochondrial Apaf-1 and Cyto C expressions in a time-dependent manner. (B and C) Expressions of mito-

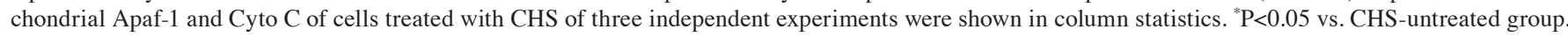
Cyto C, cytochorme c.

cells through the mitochondria-mediated ROS-p38-p53 pathway (22). In this study, the effects of a triterpenoid saponin extracted from Clematis on the growth and apoptosis of human breast cancer cells and its underlying mechanism were investigated.

CHS significantly reduced the mitochondrial Apaf-1 and Cyto $\mathrm{C}$ level. It also increased the activities of caspase-3 and -9. Mitochondria play a core role in the progression of cellular apoptosis. The cellular stress response or apoptotic signals can cause mitochondria to release Cyto $\mathrm{C}$ to induce apoptosis (23). CHS may induce mitochondria to release Cyto $\mathrm{C}$, which acts as an apoptosis inducer to form apoptosomes with Apaf-1, caspase-9, and ATP/dATP. As a result, caspase-3 is recruited and activated, triggering a caspase cascade and subsequent apoptosis $(24,25)$.

Mitochondrial apoptotic pathway was reported widely for the actions of triterpenoid saponins in other human cancers including liver cancer (26-28), gastric cancer (29), esophageal cancer (30), and colorectal cancer (31). However, studies about mitochondrial apoptotic activity in breast cancer of triterpenoid saponins are scarce, most of which focus on ginsenosides. For example, Ginsenoside Rh2 inhibited viability of both MCF-7 and MDA-MB-231 human breast cells by mitochondrial pathway (32). Ginsenoside F2 induced apoptosis in breast cancer stem cells via mitochondria pathway (33). Moreover, $\alpha$-hederin, a triterpenoid saponin similar to CHS, induced apoptosis via mitochondrial perturbations $(34,35)$, substantiating our findings as a possible common mechanistic pathway of triterpenoid saponins-induced apoptosis.

However, to the best of our knowledge, there are no studies on the effects of hederagenin saponin isolated from Clematis on breast cancer cells. In this study, we found that CHS had a strong cytotoxic effect on MDA-MB-231 and MCF-7 breast cancer cells, and can also cause apoptosis in breast cancer cells. CHS significantly reduced the mitochondrial Apaf-1 and Cyto $\mathrm{C}$ leveland also increased the activities of caspase-3 and -9. This indicates that similar to numerous types of triterpenoid saponins, CHS induces the apoptosis of tumor cells via the mitochondrial pathway.

Natural plants are a treasure trove of resources for antitumor drug development. Developing natural plant-derived antitumor drugs with definitive efficacy, high efficacy, and low-toxicity is a promising research direction for breast cancer treatment. However, the use of Chinese medicinal herbs for tumor treatment is currently undeveloped and unsystematic, with treatment methods varying largely, mostly on a case-by-case basis. The standardization of TCMs for clinical applications requires a large number of rigorous in vitro and in vivo studies. Domestic and international studies on the reactive monomer substances from Clematis ganpiniana are relatively few, and even fewer studies investigate the effect and the underlying mechanisms of the antitumor activity of Clematis ganpiniana. This study analyzed the antitumor function of CHS, a type of triterpenoid saponin extracted from Clematis ganpiniana, and the underlying mechanisms. The results suggest that $\mathrm{CHS}$ offers great potential as a new anti-breast cancer drug.

\section{Acknowledgements}

This study was supported by Natural Science Foundation of China (grant nos. 81502294, 81572595, 81272916 and 81602336) and Changzhou Sci and Tech Program (grant no. CJ20159044). 


\section{References}

1. Siegel RL, Miller KD and Jemal A: Cancer statistics, 2016. CA Cancer J Clin 66: 7-30, 2016.

2. Song JL, Chen C, Yuan JP and Sun SR: Progress in the clinical detection of heterogeneity in breast cancer. Cancer Med 5 : 3475-3488, 2016

3. Liedtke C and Kolberg HC: Systemic therapy of advanced/metastatic breast cancer-current evidence and future concepts. Breast Care (Basel) 11: 275-281, 2016.

4. Krol M, Pawłowski KM, Majchrzak K, Szyszko K and Motyl T: Why chemotherapy can fail? Pol J Vet Sci 13: 399-406, 2010

5. Karikas GA: Anticancer and chemopreventing natural products: Some biochemical and therapeutic aspects. J BUON 15: 627-638, 2010.

6. Cragg GM and Newman DJ: Natural products: A continuing source of novel drug leads. Biochim Biophys Acta 1830: 3670-3695, 2013

7. Yang J, Yuan D, Xing T, Su H, Zhang S, Wen J, Bai Q and Dang D: Ginsenoside Rh2 inhibiting HCT116 colon cancer cell proliferation through blocking PDZ-binding kinase/T-LAK cell-originated protein kinase. J Ginseng Res 40: 400-408, 2016.

8. Lin CY, Chang TW, Hsieh WH, Hung MC, Lin IH, Lai SC and Tzeng YJ: Simultaneous induction of apoptosis and necroptosis by tanshinone IIA in human hepatocellular carcinoma HepG2 cells. Cell Death Discov 2: 16065, 2016.

9. Peltier S, Oger JM, Lagarce F, Couet W and Benoît JP: Enhanced oral paclitaxel bioavailability after administration of paclitaxel-loaded lipid nanocapsules. Pharm Res 23: 1243-1250, 2006.

10. Wang TH, Wang HS and Soong YK: Paclitaxel-induced cell death: Where the cell cycle and apoptosis come together Cancer 88: 2619-2628, 2000.

11. Ding Q, Yang LX, Yang HW, Jiang C, Wang YF and Wang S: Cytotoxic and antibacterial triterpenoids derivatives from Clematis ganpiniana. J Ethnopharmacol 126: 382-385, 2009.

12. Cheng L, Xia TS, Wang YF, Zhou W, Liang XQ, Xue JQ, Shi L, Wang $Y$ and Ding Q: The apoptotic effect of D rhamnose $\beta$-hederin, a novel oleanane-type triterpenoid saponin on breast cancer cells. PLoS One 9: e90848, 2014.

13. Podolak I, Galanty A and Sobolewska D: Saponins as cytotoxic agents: A review. Phytochem Rev 9: 425-474, 2010.

14. Augustin JM, Kuzina V, Andersen SB and Bak S: Molecular activities, biosynthesis and evolution of triterpenoid saponins. Phytochemistry 72: 435-457, 2011

15. Ma G, Guo W, Zhao L, Zheng Q, Sun Z, Wei J, Yang J and $\mathrm{Xu} \mathrm{X}$ : Two new triterpenoid saponins from the root of Platycodon grandiflorum. Chem Pharm Bull (Tokyo) 61 101-104, 2013.

16. Bishayee A, Ahmed S, Brankov N and Perloff M: Triterpenoids as potential agents for the chemoprevention and therapy of breast cancer. Front Biosci (Landmark Ed) 16: 980-996, 2011.

17. Rabi T, Huwiler A and Zangemeister-Wittke U: AMR-Me inhibits PI3K/Akt signaling in hormone-dependent MCF-7 breast cancer cells and inactivates NF- $\mathrm{KB}$ in hormone-independent MDA-MB-231 cells. Mol Carcinog 53: 578-588, 2014.

18. Xiong J, Cheng G, Tang H, Zhen HN and Zhang X: Ardipusilloside I induces apoptosis in human glioblastoma cells through a caspase-8-independent FasL/Fas-signaling pathway. Environ Toxicol Pharmacol 27: 264-270, 2009.

19. Cohen GM: Caspases: The executioners of apoptosis. Biochem J 326: 1-16, 1997.
20. Kim R, Emi M and Tanabe K: Caspase-dependent and -independent cell death pathways after DNA damage (Review). Oncol Rep 14: 595-599, 2005.

21. Peng H, Lv H, Wang Y, Liu YH, Li CY, Meng L, Chen F and Bao JK: Clematis montana lectin, a novel mannose-binding lectin from traditional Chinese medicine with antiviral and apoptosis-inducing activities. Peptides 30: 1805-1815, 2009.

22. Liu B, Cheng Y, Zhang B, Bian HJ and Bao JK: Polygonatum cyrtonema lectin induces apoptosis and autophagy in human melanoma A375 cells through a mitochondria-mediated ROS-p38-p53 pathway. Cancer Lett 275: 54-60, 2009.

23. Suen DF, Norris KL and Youle RJ: Mitochondrial dynamics and apoptosis. Genes Dev 22: 1577-1590, 2008

24. Merino D, Lok SW, Visvader JE and Lindeman GJ: Targeting BCL-2 to enhance vulnerability to therapy in estrogen receptor-positive breast cancer. Oncogene 35: 1877-1887, 2016.

25. Zeng M, Zheng M, Lu D, Wang J, Jiang W and Sha O: Anti-tumor activities and apoptotic mechanism of ribosome-inactivating proteins. Chin J Cancer 34: 325-334, 2015.

26. Wang QF, Chen JC, Hsieh SJ, Cheng CC and Hsu SL: Regulation of Bcl-2 family molecules and activation of caspase cascade involved in gypenosides-induced apoptosis in human hepatoma cells. Cancer Lett 183: 169-178, 2002.

27. Wang J, Zhao XZ, Qi Q, Tao L, Zhao Q, Mu R, Gu HY, Wang M, Feng $X$ and Guo QL: Macranthoside B, a hederagenin saponin extracted from Lonicera macranthoides and its anti-tumor activities in vitro and in vivo. Food Chem Toxicol 47: 1716-1721, 2009.

28. Park HM, Kim SJ, Kim JS and Kang HS: Reactive oxygen species mediated ginsenoside $\mathrm{Rg} 3$ - and $\mathrm{Rh} 2$-induced apoptosis in hepatoma cells through mitochondrial signaling pathways. Food Chem Toxicol 50: 2736-2741, 2012.

29. Chun J, Ha IJ and Kim YS: Antiproliferative and apoptotic activities of triterpenoid saponins from the roots of Platycodon grandiflorum and their structure-activity relationships. Planta Med 79: 639-645, 2013.

30. Mo S, Xiong H, Shu G, Yang X, Wang J, Zheng C, Xiong W and Mei Z: Phaseoloideside E, a novel natural triterpenoid saponin identified from entada phaseoloides, induces apoptosis in Ec-109 esophageal cancer cells through reactive oxygen species generation. J Pharmacol Sci 122: 163-175, 2013.

31. Wang CZ, Li XL, Wang QF, Mehendale SR, Fishbein AB, Han AH, Sun S and Yuan CS: The mitochondrial pathway is involved in American ginseng-induced apoptosis of SW-480 colon cancer cells. Oncol Rep 21: 577-584, 2009.

32. Choi S, Oh JY and Kim SJ: Ginsenoside Rh2 induces Bcl-2 family proteins-mediated apoptosis in vitro and in xenografts in vivo models. J Cell Biochem 112: 330-340, 2011.

33. Mai TT, Moon J, Song Y, Viet PQ, Phuc PV, Lee JM, Yi TH, Cho $\mathrm{M}$ and Cho SK: Ginsenoside F2 induces apoptosis accompanied by protective autophagy in breast cancer stem cells. Cancer Lett 321: 144-153, 2012.

34. Swamy SM and Huat BT: Intracellular glutathione depletion and reactive oxygen species generation are important in alpha-hederin-induced apoptosis of P388 cells. Mol Cell Biochem 245: 127-139, 2003.

35. Cheng L, Xia TS, Wang YF, Zhou W, Liang XQ, Xue JQ, Shi L, Wang Y, Ding Q and Wang M: The anticancer effect and mechanism of $\alpha$-hederin on breast cancer cells. Int J Oncol 45: 757-763, 2014.

This work is licensed under a Creative Commons Attribution-NonCommercial-NoDerivatives 4.0 International (CC BY-NC-ND 4.0) License. 